\title{
In ovo feeding of carbohydrates and incubated at a high incubation temperature on hatchability and glycogen status of chicks
}

\author{
T.M. Shafey ${ }^{1 \#}$, M.A. Alodan ${ }^{1}$, I.M. Al-Ruqaie ${ }^{2} \&$ M.A. Abouheif ${ }^{1}$ \\ ${ }^{1}$ Department of Animal Production, King Saud University, P.O. Box 2460, Riyadh 11451, Saudi Arabia \\ ${ }^{2}$ National Centre for Agriculture Technology, King Abdulaziz City for Science and Technology, P.O. Box 6086, \\ Riyadh 11442, Saudi Arabia
}

Copyright resides with the authors in terms of the Creative Commons Attribution 2.5 South African Licence.

See: http://creativecommons.org/licenses/by/2.5/za

Condition of use: The user may copy, distribute, transmit and adapt the work, but must recognise the authors and the South African Journal of Animal Science.

\begin{abstract}
Eggs from a meat-type breeder flock at 29 and 35 weeks of age were used in two trials to investigate the effects of in ovo feeding of carbohydrates (CHO) and high incubation temperature $\left(37.5 \mathrm{vs} .38 .5{ }^{\circ} \mathrm{C}\right.$ (HIT)) during days 16 to 21 of incubation on hatchability traits, chick weight at hatch as an absolute value or as a percentage of egg weight (CWTP), hatching time, glycogen concentration in the liver and pectoral muscle, and glycogen index of hatched chicks. The treatments were a non-injected control, a positive control where saline was injected, or saline with a CHO mixture at 50,100, 150, 200 and $250 \mathrm{mg} / \mathrm{egg}$. The CHO mixture was maltose, sucrose and dextrin in a proportion of $1: 1: 8$ by weight. As a result of this study, in ovo feeding of $\mathrm{CHO}$ increased CWTP without altering hatchability traits. Hatched chicks from eggs injected with $250 \mathrm{mg} \mathrm{CHO} / \mathrm{egg}$ had a higher liver glycogen content and glycogen index than those of the control treatments. The high incubation temperature reduced chick weight, hatching time, liver glycogen and glycogen index of the hatched chicks. In ovo feeding of 100 and above mg CHO/egg overcame the negative effects of HIT. Hatched chicks from older hens had a lower concentration of liver glycogen and glycogen index than those of younger hens. It was concluded that in ovo feeding of $\mathrm{CHO}$ improved the weight and glycogen index of hatched chicks and those of the HIT treatment, and older hens negatively affected the glycogen index of hatched chicks.
\end{abstract}

Keywords: Broiler eggs, glycogen, incubation, liver, pectoral muscle

\# Corresponding author: tmshafey@ksu.edu.sa

\section{Introduction}

Avian embryogenesis is an external process. Chicken embryos are dependent on the nutrients within the egg, which provide the energy and building blocks required for the metabolic needs of the growing embryo during its normal 21-day incubation (Foye et al., 2006). However, oxygen is the only nutrient not derived from the egg. Therefore, the nutrient composition of the egg determines the success of development and hatching of a healthy chick. Glucose is the predominant energy source during the first week of embryonic growth (Moran, 2007), whereas a large portion of the carbohydrate glucose is utilized in the first week of incubation. Whilst fatty acids of yolk lipids are the predominant energy source during the second half of incubation (Noble \& Cocchi, 1990; Sato et al., 2006), a large mobilization of yolk nutrients into the embryo occurs during the peri-hatch period (Richards, 1991; Vieira \& Moran, 1999) and is utilized during the hatching process (Sell, 1996; Uni et al., 1998; Chotinsky et al., 2001; Geyra et al., 2001). The ability of embryos to utilize yolk nutrients is compromised by the limited availability of oxygen for aerobic metabolism until lung respiration is initiated (Moran, 2007). Therefore embryos gradually decrease fat metabolism and increase glycogen metabolism (Moran, 2007). Glycogen stored in the liver and muscles of embryos is the main energy source during the hatching process (Donaldson, 1995; Moran, 2007). However, 
at this stage of incubation, glycogen is utilized in greater amount in order to meet the high energy demand of the hatching process, and consequently glycogen reserves in the embryo are significantly depleted at the end of incubation.

The chicken embryo is very sensitive to a deficiency of energy during the hatching process. This deficiency can result is a weak hatchling and in more sever condition can result in embryonic death. Energy supply is therefore a limiting factor for a successful exit from the egg. Improving the glycogen reserves in the embryo will provide the critical energy needed for hatching. Many attempts have been made to improve the glycogen status of the embryos at the end of the incubation period and at hatching by employing in ovo feeding (Coles et al., 1999; 2003; Ohta et al., 1999; Tako et al., 2004; Uni et al., 2005; Shafey et al., 2009; 2010). It has been suggested that the consequent improvement in chick growth relates to the greater maturity of the gastro intestinal tract at hatch which supports higher rates of nutrient absorption.

Factors involved in the switching from aerobic to anaerobic metabolism and the altering of the balance of glycogen reserves of the embryo include temperature at the last stage of incubation. Increasing temperature at the end of the egg incubation period produced poor quality chicks, large residual of yolks, lower protein deposition in the embryo, higher utilization of glycogen and reduced hatchling development and period of incubation (Wineland et al., 2000a; b; Wineland \& Christensen, 2001; Lourens et al., 2005; 2007; Leksrisompong et al., 2007; Molenaar et al., 2009; Piestun et al., 2009). In addition, the uptake and secretion of lipids and proteins by the yolk sac membrane appear to be impaired in situations such as elevated temperatures or decreased oxygen levels during incubation, and that lead to high embryonic mortality (Speake \& Powell, 2003; Powell et al., 2004).

Therefore, this study explored the hypothesis that in ovo feeding may overcome the negative effects of increased temperature during the last stage of egg incubation. The effects of in ovo feeding of carbohydrates (CHO) on hatchability traits and glycogen status of hatched broiler chickens from eggs incubated under high temperature during the last stage of incubation were investigated.

\section{Materials and Methods}

A total of 800 fresh laid eggs of comparable weight produced by a flock of 29-week-old hens from a meat-type breeder (Ross, Al-Wady Company, Al-Riyadh, Saudi Arabia), were used in the first trial. Eggs were numbered, weighed individually and distributed into weight classes. Eggs were set in a Maino, forcedraft incubator (Model II, Maino Enrico, Co., Rome, Italy) and incubated at $37.5{ }^{\circ} \mathrm{C}$ and $55 \%$ relative humidity. The eggs were turned every $2 \mathrm{~h}$ and examined by candling at $16 \mathrm{~d}$ of incubation. Infertile eggs and eggs containing dead embryos were removed. After examination, 672 eggs were evenly assigned into 56 replicates of 12 eggs of equal weight per replicate. The replicates were assigned randomly into two groups of 28 replicates for the two treatments of incubation temperatures, $37.5{ }^{\circ} \mathrm{C}$ (control) and $38.5{ }^{\circ} \mathrm{C}$ (high temperature, HIT) until the end of incubation period. The control group remained in the incubator described above and the HIT group was placed in another identical incubator. The relative humidity of the incubators was set at $55 \%$. At 17.5 days of incubation, eggs were in ovo injected with $\mathrm{CHO}$. The in ovo treatments were two control treatments: non-injected (negative control, NC), and injected with $0.9 \%$ sterilised saline (positive control, PC) and five other treatments in which sterilised saline containing 50, 100, 150, 200 or $250 \mathrm{mg}$ of mixed sugars was injected. The CHO mixtures were prepared by dissolving maltose, sucrose and dextrin (Sigma-Aldrich, Inc., St. Louis, MO, USA) in proportion of $1: 1: 8$ by weight, respectively, in sterilised saline. The wide end of the eggshell was disinfected with $70 \%$ isopropyl alcohol where-upon an injection hole was pierced. The $0.5 \mathrm{~mL}$ of solution was injected into the yolk sac using a $25 \mathrm{~mm}$ x 21-G needle. After injection, the hole was sealed with melted paraffin wax and the eggs were returned to the incubators.

Eggs were transferred to separate sections in the hatching tray on the morning of d 19 of incubation, for chick identification at hatch. The hatching tray was divided into individual hatching sections using thin sheets of mesh wires. The hatching compartments of the two incubators were set at $37{ }^{\circ} \mathrm{C}$ and $38{ }^{\circ} \mathrm{C}$ for the control and HIT treatments, respectively, with a relative humidity $65 \%$ until the end of $\mathrm{d} 21$ of incubation. At this time chicks, pips (unhatched eggs with live or dead chicks) and dead embryos (unhatched eggs with unbroken shell) were counted. Per cent hatchability was calculated on the basis of the number of hatched chicks as a percentage of the in ovo treated eggs per replicate. Hatching time was recorded every $12 \mathrm{~h}$. Chicks were observed at 12-h intervals from 444 to $504 \mathrm{~h}$ of incubation and hatching weight was recorded to the nearest $0.1 \mathrm{~g}$. At the end of the incubation period, six chicks were randomly selected from each experimental treatment. The weight of the chick was determined, and the liver and pectoral muscle (PM) 
were collected and weighed. Samples of liver and PM were frozen in liquid nitrogen immediately after collection and stored at $-60{ }^{\circ} \mathrm{C}$ for glycogen determination. Samples of liver and PM $(0.25 \mathrm{~g})$ were added to $1 \mathrm{~mL}$ of $8 \%$ perchloric acid, homogenised (in ice) for $1 \mathrm{~min}$, and centrifuged at $14000 \mathrm{x} g$ at $4{ }^{\circ} \mathrm{C}$ for 30 min. The supernatant was removed, and $1 \mathrm{ml}$ petroleum ether $\left(60-80^{\circ} \mathrm{C}\right)$ was added. After being mixed, the petroleum ether fraction was removed, and samples from the bottom layer were transferred to a new tube for glycogen determination. Glycogen was measured colorimetrically using an iodine - potassium iodide reagent (an iodine $\left(\mathrm{I}_{2}-\mathrm{KI}\right)$ solution containing saturated $\mathrm{CaCl}_{2}$ ) (Dreiling et al., 1987) in a spectrophotometer set at $460 \mathrm{~nm}$. The incubation trial was repeated with eggs produced at 35 weeks of age. Eggs were treated as in trial 1. A total of 728 eggs were evenly assigned to 56 replicates of 13 eggs of equal weight per replicate.

Measurements were made of hatchability traits (per cent hatchability and hatchability failures (pips with live embryos, pips with dead embryos, dead embryos)), chick weight at hatch expressed as an absolute value (CWT) or as a percentage of egg weight (CWTP), hatching period, liver and PM weights and glycogen concentration, and glycogen index of hatched chicks $(\mathrm{mg} / \mathrm{g}$ ) (calculated as the sum of the total liver and PM glycogen (mg) divided by body mass (g)). There were no significant differences among the in ovo treatments in the hatchability traits, and hatching period of eggs, and between the two trials in CWTP. Therefore, data from trials 1 and 2 were combined for final analysis. Data were arranged in a 7 × 2 × 2 factorial arrangement for in ovo treatment, age and trial as main effects and their two-way interactions fitted into the model. All per cent data were transformed using arc sine square root percentage transformation before analysis. All statistical analysis was performed using the Statistical Analysis System (SAS, 1985).

\section{Results}

The effects of in ovo feeding of $\mathrm{CHO}$ and high temperature during the last stage of incubation on hatchability traits, and weight and glycogen status of hatched chicks are shown in Tables 1 to 3, respectively. In ovo feeding of CHO increased $(P<0.01)$ CWTP, whilst in ovo feeding of 50, 150, 200 and $250 \mathrm{mg}$ $\mathrm{CHO} /$ ggg increased CWT when compared with those of the control treatments. In ovo feeding of 200 and $250 \mathrm{mg} \mathrm{CHO/egg} \mathrm{treatments} \mathrm{had} \mathrm{significantly}(P<0.01)$ lower hatching times than that of in ovo of $50 \mathrm{mg}$ $\mathrm{CHO} /$ ggg treatment, while hatching times of the other treatments were intermediate. Chicks of the negative control treatment had a lower weight $(P<0.01)$ at hatch $($ CWT and CWTP) than those of the in ovo treatments of $\mathrm{CHO}$ and a higher liver weight percentage of hatched chick than those of the other treatments. Hatched chicks from the positive control treatment had a significantly $(P<0.01)$ higher liver weight percentage than those on the in ovo of 50,100, 150 and $200 \mathrm{mg}$ CHO/egg treatments. Hatched chicks from eggs injected with $250 \mathrm{mg} \mathrm{CHO/egg} \mathrm{had} \mathrm{a} \mathrm{higher}(P<0.01)$ liver glycogen concentration and glycogen index than those of the control and the 50, 100 and $200 \mathrm{mg} \mathrm{CHO} / \mathrm{egg}$ in ovo treatments. In ovo treatments of 150, 200 and $250 \mathrm{mg} \mathrm{CHO/egg} \mathrm{treatments} \mathrm{increased}(P<0.05)$ liver glycogen concentration and glycogen index of hatched chicks when compared with those of the control and in ovo at $50 \mathrm{mg} \mathrm{CHO/egg} \mathrm{treatments.}$

Increasing temperature during the last stage of incubation reduced $(P<0.05)$ hatchability, hatching time and chick weight (CWT or CWTP), glycogen concentration in the liver $(P<0.01)$ and glycogen index of hatched chicks $(P<0.05)$. Older hens (Trial 2 vs. Trial 1$)$ produced significantly $(P<0.01)$ heavier eggs, CWT and PM glycogen concentration $(P<0.05)$, and a lower liver glycogen concentration, and glycogen index of hatched chicks when compared with those of younger hens $(P<0.01)$. There was significant interaction $(P<0.01)$ between in ovo feeding of CHO and incubation temperature on CWT and CWTP, and liver glycogen concentration and glycogen index of hatched chicks $(P<0.05)$. In ovo feeding of 100 and above $\mathrm{mg} \mathrm{CHO/egg}$ alleviated the growth depression and restored liver glycogen concentration and glycogen index of hatched chicks incubated under high temperature when compared with those of the control and in ovo feeding at $50 \mathrm{mg} \mathrm{CHO/egg} \mathrm{treatments.}$

In ovo treatment of $\mathrm{CHO}$ did not significantly influence hatchability traits, hatching time and PM glycogen concentration of hatched chicks when compared with those of the control treatments. There was no significant difference between the control and the $50 \mathrm{mg}$ CHO/egg in ovo treatments in PM weight percentage of the hatched chick, between the in ovo treatments of 150 and $200 \mathrm{mg} \mathrm{CHO} / \mathrm{egg}$ treatments in any of the measurements, among in ovo treatments of CHO in CWT and CWTP, among the control and in ovo of 50 and $100 \mathrm{mg} \mathrm{CHO/egg} \mathrm{treatments} \mathrm{in} \mathrm{liver} \mathrm{glycogen} \mathrm{concentration,} \mathrm{and} \mathrm{glycogen} \mathrm{index} \mathrm{of} \mathrm{hatched}$ 
Table 1 Mean per cent of hatchability and hatchability failures of eggs from meat-type breeder birds subjected to in ovo feeding of carbohydrates $(\mathrm{CHO})$ and incubated under high temperature during the late stage of incubation

\begin{tabular}{|c|c|c|c|c|c|}
\hline $\begin{array}{l}\text { Main effect } \\
\text { means }^{1}\end{array}$ & $\begin{array}{c}\text { Hatch of } \\
\text { fertile eggs } \\
(\%)\end{array}$ & $\begin{array}{c}\text { Late embryo } \\
\text { deaths } \\
(\%)\end{array}$ & $\begin{array}{c}\text { Pipped with } \\
\text { live embryos } \\
(\%)\end{array}$ & $\begin{array}{c}\text { Pipped with } \\
\text { dead embryos } \\
(\%)\end{array}$ & $\begin{array}{l}\text { Hatching } \\
\text { time } \\
(\mathrm{h}) \\
\end{array}$ \\
\hline \multicolumn{6}{|c|}{ In ovo feeding (TRT) $)^{2}(\mathrm{mg} \mathrm{CHO} / \mathrm{egg})$} \\
\hline Control $(+)^{3}$ & $90.4 \pm 1.09$ & $8.0 \pm 0.93$ & $0.8 \pm 0.46$ & $0.7 \pm 0.38$ & $487.7^{\mathrm{ab}} \pm 1.89$ \\
\hline Control $(+)^{4}$ & $90.9 \pm 2.50$ & $7.2 \pm 2.59$ & $0.8 \pm 0.50$ & $1.0 \pm 0.38$ & $490.2^{\mathrm{ab}} \pm 2.86$ \\
\hline 50 & $91.1 \pm 1.89$ & $6.5 \pm 1.95$ & $1.4 \pm 0.44$ & $1.0 \pm 0.46$ & $494.2^{\mathrm{a}} \pm 2.04$ \\
\hline 100 & $92.1 \pm 2.44$ & $6.9 \pm 1.76$ & $0.4 \pm 0.47$ & $0.6 \pm 0.59$ & $485.0^{\mathrm{ab}} \pm 3.51$ \\
\hline 150 & $91.0 \pm 1.62$ & $6.9 \pm 2.03$ & $1.1 \pm 0.61$ & $1.00 \pm 0.61$ & $486.7^{\mathrm{ab}} \pm 3.19$ \\
\hline 200 & $92.3 \pm 1.53$ & $6.8 \pm 1.74$ & $0.4 \pm 0.39$ & $0.5 \pm 0.23$ & $479.5^{\mathrm{b}} \pm 3.95$ \\
\hline 250 & $91.9 \pm 1.84$ & $5.8 \pm 1.17$ & $1.3 \pm 0.64$ & $1.0 \pm 0.61$ & $480.6^{\mathrm{b}} \pm 4.63$ \\
\hline \multicolumn{6}{|c|}{ Incubation temperature $(\mathrm{TM})^{5}$} \\
\hline $37.5^{\circ} \mathrm{C}$ & $93.0 \pm 1.90$ & $5.6 \pm 1.86$ & $0.8 \pm 0.59$ & $0.6 \pm 0.49$ & $489.3 \pm 1.80$ \\
\hline $38.5^{\circ} \mathrm{C}$ & $89.8^{*} \pm 1.94$ & $8.1 \pm 1.86$ & $1.0 \pm 0.60$ & $1.0 \pm 0.53$ & $483.3 * \pm 1.76$ \\
\hline \multicolumn{6}{|l|}{ Trial $(\mathrm{TR})^{6}$} \\
\hline 1 & $90.1 \pm 1.98$ & $7.9 \pm 1.94$ & $1.0 \pm 0.56$ & $1.0 \pm 0.52$ & $484.7 \pm 1.92$ \\
\hline 2 & $92.6 \pm 1.61$ & $5.9 \pm 1.64$ & $0.8 \pm 0.63$ & $0.7 \pm 0.47$ & $487.8 \pm 1.76$ \\
\hline \multicolumn{6}{|c|}{ Source of variation } \\
\hline TRT $^{2}$ & NS & NS & NS & NS & $*$ \\
\hline $\mathrm{TM}^{5}$ & $*$ & NS & NS & NS & $*$ \\
\hline $\mathrm{TR}^{6}$ & NS & NS & NS & NS & NS \\
\hline TRT x TM & NS & NS & NS & NS & NS \\
\hline TRT $x$ TR & NS & NS & NS & NS & NS \\
\hline TM $x$ TR & NS & NS & NS & NS & NS \\
\hline
\end{tabular}

\footnotetext{
${ }^{1}$ Values are Means \pm SE.

${ }^{2}$ TRT - In ovo feeding of carbohydrate (CHO). CHO was dissolved in distilled sterilized saline water $(0.9 \%$ $\mathrm{NaCl}$;

${ }^{3}$ Non- injected control eggs;

${ }_{5}^{4}$ In ovo injection with distilled sterilized saline water $(0.9 \% \mathrm{NaCl})$;

${ }^{5}$ Incubation temperature;

${ }^{6} \mathrm{TR}$ - Trial. Eggs obtained from Ross flock at the age of 29 and 35 weeks of age in trials 1 and 2, respectively.

${ }^{\mathrm{a}, \mathrm{b}}$ Means within column with different superscripts are significantly different $(P<0.05)$;

* Significantly different $(P<0.05)$; NS - Non significant.
}

chicks, in ovo treatments of 100, 150, 200 and $250 \mathrm{mg}$ CHO/egg treatments in PM weight percentage of hatched chick. Incubation temperature did not significantly influence liver and PM percentages of hatched chick weight, PM glycogen concentration and hatchability failures (pips (unhatched eggs with live or dead chicks) and dead embryos). Trial or age of laying hens did not influence hatchability traits, CWTP and liver and PM percentages of hatched chick weight. 
Table 2 Chick hatching weight express on an absolute and percentage basis (chick hatching weight*100/egg weight) of meat-type breeder eggs subjected to in ovo feeding of carbohydrates (CHO) and incubated under high temperature during the late stage of incubation

\begin{tabular}{|c|c|c|c|}
\hline Main effect means ${ }^{1}$ & $\begin{array}{c}\text { Egg weight } \\
(\mathrm{g})\end{array}$ & $\begin{array}{c}\text { Chick weight } \\
(\mathrm{g})\end{array}$ & $\begin{array}{c}\text { Chick weight } \\
(\%)\end{array}$ \\
\hline \multicolumn{4}{|c|}{ In ovo feeding (TRT) $)^{2}$ (mg CHO/egg) } \\
\hline Control $(+)^{3}$ & $56.0 \pm 0.32$ & $38.5^{\mathrm{c}} \pm 0.21$ & $68.8^{\mathrm{b}} \pm 0.24$ \\
\hline Control $(+)^{4}$ & $55.9 \pm 0.26$ & $38.6^{\mathrm{bc}} \pm 0.22$ & $69.0^{\mathrm{b}} \pm 0.23$ \\
\hline 50 & $56.0 \pm 0.29$ & $39.2^{\mathrm{a}} \pm 0.21$ & $70.1^{\mathrm{a}} \pm 0.18$ \\
\hline 100 & $56.0 \pm 0.27$ & $39.1^{\mathrm{ab}} \pm 0.22$ & $69.8^{\mathrm{a}} \pm 0.23$ \\
\hline 150 & $55.9 \pm 0.26$ & $39.1^{\mathrm{a}} \pm 0.23$ & $70.0^{\mathrm{a}} \pm 0.22$ \\
\hline 200 & $55.8 \pm 0.27$ & $39.1^{\mathrm{a}} \pm 0.23$ & $70.1^{\mathrm{a}} \pm 0.20$ \\
\hline 250 & $56.1 \pm 0.26$ & $39.5^{\mathrm{a}} \pm 0.21$ & $70.3^{\mathrm{a}} \pm 0.19$ \\
\hline \multicolumn{4}{|c|}{ Incubation temperature $(\mathrm{TM})^{5}$} \\
\hline $37.5^{\circ} \mathrm{C}$ & $55.9 \pm 0.11$ & $39.3 \pm 0.10$ & $70.3 \pm 0.11$ \\
\hline $38.5^{\circ} \mathrm{C}$ & $56.0 \pm 0.10$ & $38.7 * * \pm 0.08$ & $69.2 * * \pm 0.09$ \\
\hline \multicolumn{4}{|l|}{ Trial $(\mathrm{TR})^{6}$} \\
\hline 1 & $54.0 \pm 0.13$ & $37.7 \pm 0.11$ & $69.7 \pm 0.13$ \\
\hline 2 & $57.2 * * \pm 0.11$ & $39.9^{* *} \pm 0.09$ & $69.7 \pm 0.11$ \\
\hline
\end{tabular}

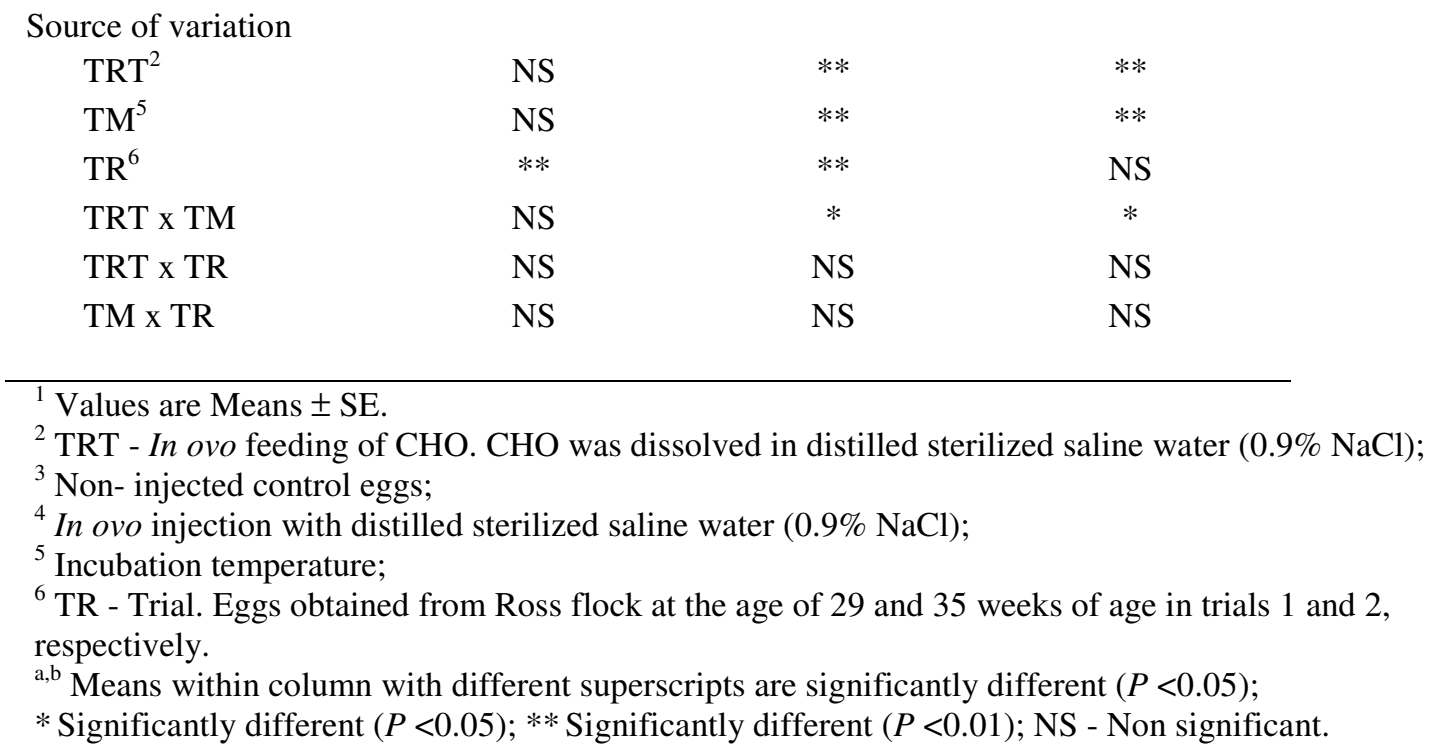

\section{Discussion}

Results from this study indicated that in ovo feeding of $\mathrm{CHO}$ improved chick hatching weight as a proportion of egg weight without any effect on hatchability traits. These results were in agreement with Tako et al. (2004) who found that in ovo feeding of $1 \mathrm{~mL} / \mathrm{egg}$ of CHO (25 g of maltose/L, $25 \mathrm{~g}$ of sucrose/L, 200 $\mathrm{g}$ of dextrin/L, and $5 \mathrm{~g}$ of $\mathrm{NaCl} / \mathrm{L})$ or $\mathrm{CHO}$ plus beta-hydroxy-beta-methylbutyrate, $\mathrm{HMB}(1 \mathrm{~g}$ of HMB/L in $5 \mathrm{~g}$ of $\mathrm{NaCl} / \mathrm{L}$ ) at 17 days of incubation improved the weight and intestinal development of hatched chicks. Smirnov et al. (2006) concluded that the presence of CHO in the intestinal lumen of the chick embryo improved intestinal morphology and consequently nutrient absorption. Recently, Zhai et al. (2011) reported that in ovo feeding of 0.1 to $1 \mathrm{~mL} / \mathrm{egg}$ of $\mathrm{CHO}(0.25 \mathrm{~g} / \mathrm{mL}$ of glucose, fructose, sucrose, maltose or dextrin) 
Table 3 Mean glycogen concentration of liver of hatched chicks from meat-type breeder eggs subjected to in ovo feeding of carbohydrates $(\mathrm{CHO})$ and incubated under high temperature during the late stage of incubation

\begin{tabular}{|c|c|c|c|}
\hline \multirow[b]{2}{*}{ Main effect means ${ }^{1}$} & \multirow{2}{*}{$\begin{array}{l}\text { Chicken weight at } \\
\text { hatch } \\
(\mathrm{g})\end{array}$} & \multicolumn{2}{|c|}{ Liver } \\
\hline & & $\begin{array}{c}\text { Weight } \\
(\%)\end{array}$ & $\begin{array}{c}\text { Glycogen } \\
(\mathrm{mg} / \mathrm{g})\end{array}$ \\
\hline \multicolumn{4}{|c|}{ In ovo feeding $(\mathrm{TRT})^{2}$ (mg CHO/egg) } \\
\hline Control $(+)^{3}$ & $37.3^{c} \pm 0.34$ & $2.7^{\mathrm{a}} \pm 0.03$ & $5.2^{\mathrm{d}} \pm 0.23$ \\
\hline Control $(+)^{4}$ & $38.4^{\mathrm{ab}} \pm 0.55$ & $2.4^{\mathrm{b}} \pm 0.07$ & $5.1^{\mathrm{d}} \pm 0.25$ \\
\hline 50 & $38.7^{\mathrm{ab}} \pm 0.64$ & $2.2^{\mathrm{cd}} \pm 0.04$ & $5.1^{\mathrm{d}} \pm 0.22$ \\
\hline 100 & $37.9^{b c} \pm 0.43$ & $2.2^{\mathrm{cd}} \pm 0.07$ & $5.4^{\mathrm{cd}} \pm 0.08$ \\
\hline 150 & $39.4^{\mathrm{a}} \pm 0.46$ & $2.2^{\mathrm{d}} \pm 0.06$ & $6.4^{\mathrm{ab}} \pm 0.24$ \\
\hline 200 & $39.0^{\mathrm{a}} \pm 0.57$ & $2.2^{\mathrm{d}} \pm 0.05$ & $6.0^{\mathrm{bc}} \pm 0.27$ \\
\hline 250 & $39.2^{\mathrm{a}} \pm 0.41$ & $2.4^{\mathrm{bc}} \pm 0.04$ & $6.7^{\mathrm{a}} \pm 0.32$ \\
\hline \multicolumn{4}{|c|}{ Incubation temperature $(\mathrm{TM})^{5}$} \\
\hline $37.5^{\circ} \mathrm{C}$ & $39.0 \pm 0.22$ & $2.4 \pm 0.04$ & $5.9 \pm 0.17$ \\
\hline $38.5^{\circ} \mathrm{C}$ & $38.1^{*} \pm 0.29$ & $2.3 \pm 0.05$ & $5.5 * * \pm 0.15$ \\
\hline \multicolumn{4}{|l|}{ Trial (TR) } \\
\hline 1 & $37.5 \pm 0.21$ & $2.3 \pm 0.04$ & $5.9 \pm 0.15$ \\
\hline 2 & $39.6^{* *} \pm 0.24$ & $2.3 \pm 0.05$ & $5.4^{* *} \pm 0.14$ \\
\hline \multicolumn{4}{|l|}{ Source of variation } \\
\hline $\mathrm{TRT}^{3}$ & $* *$ & $* *$ & $* *$ \\
\hline $\mathrm{TM}^{5}$ & $* *$ & NS & $* *$ \\
\hline $\mathrm{TR}^{6}$ & $* *$ & NS & $* *$ \\
\hline TRT $x$ TM & $*$ & NS & $*$ \\
\hline TRT $x$ TR & NS & NS & NS \\
\hline $\mathrm{TM} \times \mathrm{TR}$ & NS & NS & NS \\
\hline
\end{tabular}

\footnotetext{
${ }^{1}$ Values are Means \pm SE.

${ }^{2} \mathrm{TRT}$ - In ovo feeding of CHO. CHO was dissolved in distilled sterilized saline water $(0.9 \% \mathrm{NaCl})$;

${ }^{3}$ Non-injected control eggs;

${ }^{4}$ Eggs were subjected to in ovo injection of sterilized distilled saline water $(0.9 \% \mathrm{NaCl})$;

${ }^{5}$ Incubation temperature;

${ }^{6}$ TR - Trial. Eggs obtained from Ross flock at the age of 29 and 35 weeks of age in trials 1 and 2, respectively.

a,b,c,d Means within column with different superscripts are significantly different $(P<0.05)$;

* Significantly different $(P<0.05)$; ** Significantly different $(P<0.01)$; NS - Non significant.
}

at 18.5 day of incubation did not influence rate of hatch of chicken eggs but weight of hatch chicks was positively related to injection volume when expressed on an absolute value or as a proportion of egg weight. However, Uni et al. (2005) found that in ovo feeding of CHO plus HMB ( $1 \mathrm{~mL}$ of a solution containing $25 \mathrm{~g} / \mathrm{L}$ maltose, $25 \mathrm{~g} / \mathrm{L}$ sucrose, $200 \mathrm{~g} / \mathrm{L}$ dextrin, $1 \mathrm{~g} / \mathrm{L} \mathrm{HMB}$ and $5 \mathrm{~g} / \mathrm{L} \mathrm{NaCl}$ ) increased hatchability, liver glycogen and pectoral muscle size among birds up to 25 days post-hatch. It appears that in ovo feeding of $\mathrm{CHO}$ influences the metabolism of the embryo. However, there are many factors that may influence the effect of in ovo feeding on the performance of hatching chicks. These include type of CHO used, strain of bird and egg size or stage of egg production (Shafey et al., 2009). 
Table 4 Mean glycogen concentration of muscle of hatched chicks from meat-type breeder eggs subjected to in ovo feeding of carbohydrates $(\mathrm{CHO})$ and incubated under high temperature during the late stage of incubation

\begin{tabular}{|c|c|c|c|}
\hline \multirow[b]{2}{*}{ Main effect means ${ }^{1}$} & \multicolumn{2}{|c|}{ Pectoral muscle } & \multirow[b]{2}{*}{ Glycogen index ${ }^{2}$} \\
\hline & $\begin{array}{l}\text { Weight } \\
(\%)\end{array}$ & $\begin{array}{c}\text { Glycogen } \\
(\mathrm{mg} / \mathrm{g})\end{array}$ & \\
\hline \multicolumn{4}{|c|}{ In ovo feeding $(\mathrm{TRT})^{3}$ (mg CHO/egg) } \\
\hline Control $(+)^{4}$ & $1.5^{\mathrm{b}} \pm 0.04$ & $1.4 \pm 0.06$ & $17.8^{\mathrm{c}} \pm 0.65$ \\
\hline Control $(+)^{5}$ & $1.5^{\mathrm{b}} \pm 0.03$ & $1.3 \pm 0.07$ & $16.7^{\mathrm{c}} \pm 0.46$ \\
\hline 50 & $1.5^{\mathrm{b}} \pm 0.05$ & $1.6 \pm 0.08$ & $17.4^{\mathrm{c}} \pm 0.41$ \\
\hline 100 & $1.7^{\mathrm{a}} \pm 0.04$ & $1.4 \pm 0.05$ & $18.0^{c} \pm 0.26$ \\
\hline 150 & $1.7^{\mathrm{a}} \pm 0.05$ & $1.6 \pm 0.07$ & $20.4^{\mathrm{ab}} \pm 0.55$ \\
\hline 200 & $1.7^{\mathrm{a}} \pm 0.06$ & $1.6 \pm 0.07$ & $19.6^{\mathrm{b}} \pm 0.72$ \\
\hline 250 & $1.8^{\mathrm{a}} \pm 0.07$ & $1.7 \pm 0.09$ & $21.4^{\mathrm{a}} \pm 0.83$ \\
\hline \multicolumn{4}{|c|}{ Incubation temperature $(\mathrm{TM})^{6}$} \\
\hline $37.5^{\circ} \mathrm{C}$ & $1.6 \pm 0.03$ & $1.5 \pm 0.03$ & $19.1 \pm 0.36$ \\
\hline $38.5^{\circ} \mathrm{C}$ & $1.6 \pm 0.04$ & $1.5 \pm 0.04$ & $18.4 * \pm 0.35$ \\
\hline \multicolumn{4}{|l|}{ Trial (TR) } \\
\hline 1 & $1.6 \pm 0.03$ & $1.5 \pm 0.04$ & $19.8 \pm 0.36$ \\
\hline 2 & $1.6 \pm 0.04$ & $1.6 * \pm 0.05$ & $17.7 * * \pm 0.32$ \\
\hline
\end{tabular}

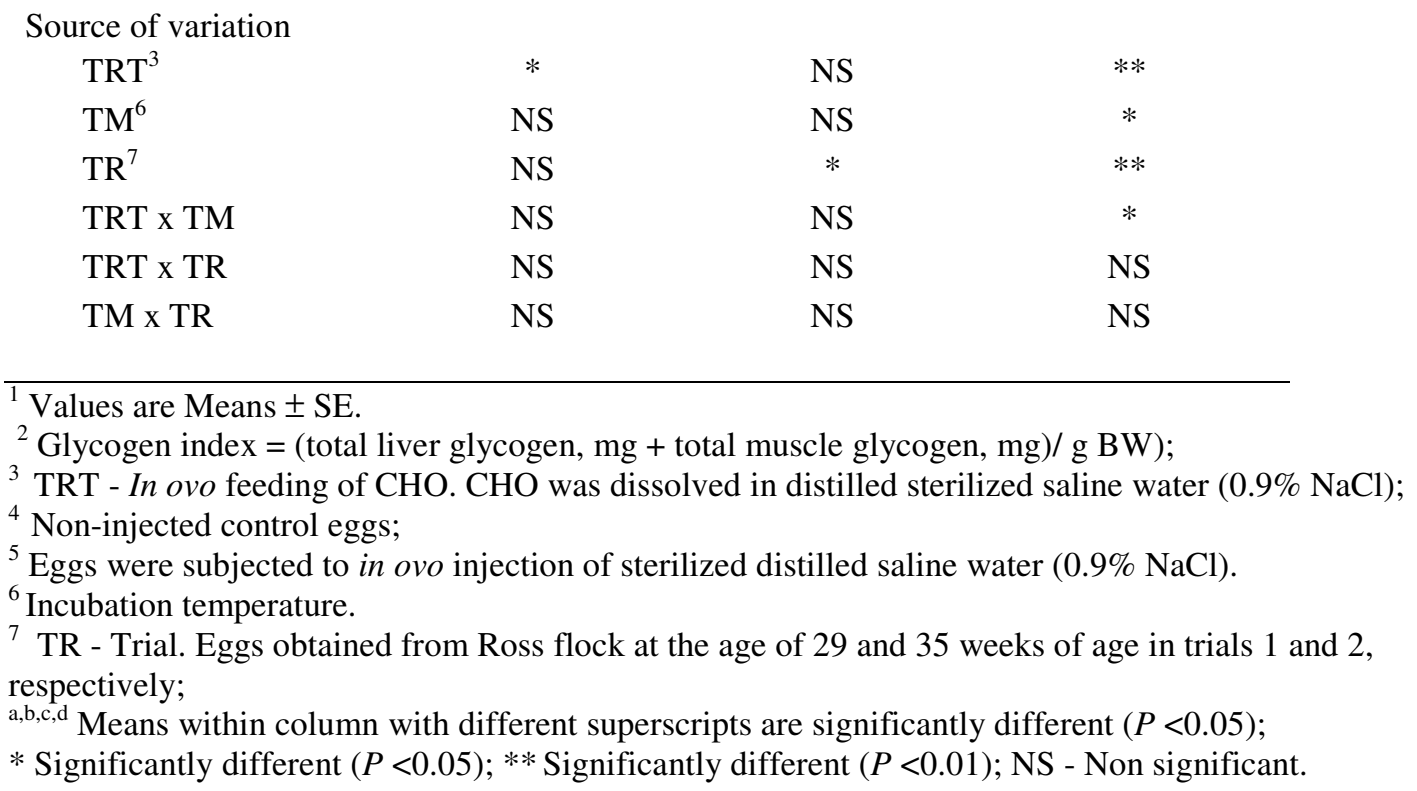

Results from the glycogen status of hatched chicks indicated that in ovo feeding of CHO increased liver glycogen concentration without any significant effect on PM glycogen. Similar findings were reported by Uni et al. (2005). In addition, the liver had a higher glycogen concentration than that of PM. It appears that liver glycogen is more sensitive to the nutritional status of the embryo than PM glycogen and the mechanisms that regulate glycogen in the muscle are not influenced by nutritional status. Similar findings were reported by Edwards et al. (1999) and Foye et al. (2006). Liver glycogen is the most important energy reserve to sustain embryos during the piping and hatching stages, and it has been used to indicate energy status in broiler and turkey (Donaldson et al., 1991; Donaldson, 1995; Christensen et al., 1996; 2001; 2003; Uni et al., 2005). 
Increasing temperature by $1{ }^{\circ} \mathrm{C}$ during the last stage of incubation (from day 16 to day 21 ) reduced absolute and proportional body weight to egg weight, liver glycogen concentration, and glycogen index of hatched chicks. These findings were in agreement with Wineland et al. (2000a; b), Wineland \& Christensen (2001) and Molenaar et al. (2009) who reported that incubating eggs at a high temperature $\left(38.6 v s .37 .5^{\circ} \mathrm{C}\right)$ early or late in incubation increased utilisation of glycogen as energy source and reduced utilisation of the yolk and embryonic growth (Lourens et al., 2005; Leksrisompong et al., 2007; Molenaar et al., 2009). Research indicates that glycogen plays an important role in response to a wide variety of stressful environments conditions (Christensen et al., 1995; Francois \& Parrou, 2001; Christensen et al., 2004). During incubation under elevated temperatures, heat stress reduces the uptake and secretion of lipids and proteins by the yolk sack membrane (Speake \& Powell, 2003; Powell et al., 2004) and increases energy requirements of the embryo (O'Dea et al., 2004) and consequently mobilization of glycogen (Puvadolpirod $\&$ Thaxton, 2000). The increase in glycogen mobilization may decrease glycogen availability for hatching. The deficiency of glycogen pushes the embryo to mobilize more muscle protein for gluconeogenesis (Puvadolpirod \& Thaxton, 2000), thereby reducing growth and development (Vieira \& Moran, 1999). The significant interaction between in ovo feeding of CHO and incubation temperature on CWT and CWTP, and liver glycogen concentration and glycogen index of hatched chicks indicated that in ovo feeding of 100 and above $\mathrm{mg} \mathrm{CHO} / \mathrm{egg}$ alleviated the growth depression and restored glycogen status of hatched chicks incubated under high temperature. These results suggest that the negative effects of high incubation temperature during the last stage of incubation are mostly related to the amount of available energy to the embryo. Low level of glycogen in the liver has been associated with a reduction in chick weight at hatch (Christensen et al., 1999; 2000; 2001). The reduction in body weight of hatched chicks under a high incubation temperature may be related to the reduction in incubation duration and consequently the short time available for development (Lourens et al., 2007) and the use of egg protein as an energy source that resulted in lower protein deposition in the embryo (Molenaar et al., 2009).

Results from the two trials (trial 2 vs. trial 1) indicated that older hens (35 vs. 29 weeks) produced heavier eggs and hatched chicks (CWT), and a lower liver glycogen concentration and glycogen index in the hatched chicks when compared with those of younger hens. Additionally, hatchability traits were not influenced by age of the hen. These observations were in agreement with Shafey (1996), Peebles et al. (2000), Silversides \& Scott (2001), Oloyo (2003), Van den Brand et al. (2004), Rizzi \& Chiericato (2005), Johnston \& Gous (2007) who showed that the egg weight increased with the hens' age. Abiola (1999) observed a positive correlation between egg size and chick hatching weight. The higher weight of hatched chicks from large eggs is due to the surplus supply of nutrients and the size of the residual yolk sac at hatch when compared with those hatched from small eggs (Lourens et al., 2006). The non significant effects of age of the flock ( 29 vs. 35 weeks) on hatchability traits were similar to those reported by Yilmaz-Dikmen \& Sahan (2009) who found that hatchability of fertile eggs was similar between breeder flock ages of 28 and 45 weeks. The difference between glycogen levels of hatched chicks from different age groups of hens may indicate differences in their metabolic rate. Embryos from old hens produced more metabolic heat and $\mathrm{CO}_{2}$ gas than those from young hens (O'Dea et al., 2004) suggesting differences in glycogen requirements. The lower glycogen level found in the hatched chicks from older hens would suggest a higher metabolic rate for embryos and consequently a higher glycogen requirement when compared with those of younger hens (O'Dea et al., 2004). Lourens et al. (2006) showed that metabolic heat production of embryo from large egg (70 vs. $56 \mathrm{~g}$ ) was greater than that of small egg during the last stage of incubation (15 - 21 day).

\section{Conclusions}

It was concluded that high incubation temperature during the last stage of incubation (16 - 21 day) and eggs from older hens negatively affected weight and glycogen status of hatched chicks without influencing hatchability traits and that of in ovo feeding of $\mathrm{CHO}$ improved the weight of hatched chicks. Whilst in ovo feeding of 100 and above $\mathrm{mg} \mathrm{CHO/egg} \mathrm{alleviated} \mathrm{the} \mathrm{growth} \mathrm{depression} \mathrm{and} \mathrm{restored} \mathrm{glycogen} \mathrm{status} \mathrm{of}$ hatched chicks incubated under high temperature.

\section{Acknowledgements}

The authors extend their appreciation to the Deanship of Scientific Research at King Saud University for funding the work through the research group project No RGP-VPP-121. 


\section{References}

Abiola, S.S., 1999. Effects of turning frequency of hen's egg in electric table-type incubator on weight losses, hatchability and mortality. Nig. Agr. J. 30, 77-82.

Chotinsky, D., Toncheva, E. \& Profirov, Y., 2001. Development of dissacharidases activity in the small intestine of broiler chickens. Br. Poult. Sci. 42, 389-393.

Christensen, V.L., Havenstein, G.B. \& Davis, G.S., 1995. Egg characteristics, carbohydrate metabolism, and thyroid hormones in late chick embryos from different genetic lines. Poult. Sci. 74, 551-62.

Christensen, V.L., Donaldson, W.E. \& McMurtry, J.P., 1996. Physiological differences in late embryos from turkey breeders at different ages. Poult. Sci. 75, 172-178.

Christensen, V.L., Donaldson, W.E. \& Nestor, K.E., 1999. Length of the plateau and pipping stages of incubation affects the physiology and survival of turkeys. Br. Poult. Sci. 40, 297-303.

Christensen, V.L., Grimes, J.L., Donaldson, W.E. \& Lerner, S., 2000. Paternal influences on turkey embryonic growth in the absence of changes in egg weight and eggshell conductance. Poult. Sci. 79, 1810-1816.

Christensen, V.L., Wineland, M.J., Fasenko, G.M. \& Donaldson, W.E., 2001. Egg storage effects on plasma glucose and supply and demand tissue glycogen concentrations of broiler embryos. Poult. Sci. 80, 1729-1735.

Christensen, V.L., Ort, D.T. \& Grimes, J.L., 2003. Physiological factors associated with weak neonatal poults (Meleagris gallopavo). Int. J. Poult. Sci. 2, 7-14.

Christensen, V.L., Wineland, M.J., Yildirum, I., Ort, D.T. \& Mann, K.M., 2004. Incubator temperature and oxygen concentration at the plateau stage affects intestinal maturation of turkey embryos. Int. J. Poult. Sci. 3, 378-385.

Coles, B.A., Croom, W.J., Brake, J., Daniel, L.R., Christensen, V.L., Phelps, C.P., Gore, A. \& Taylor, I.L., 1999. In ovo peptide YY administration improves growth and feed conversion ratios in week-old broiler chicks. Poult. Sci. 78, 1320-1322.

Coles, B.A., Croom, J., Daniel, L.R., Christensen, V.L. \& Taylor, I.L., 2003. In ovo peptide YY administration and jejunal glucose transport in hatchling turkey poults: Effects of dosage and genotype. Int. J. Poult. Sci. 2, 1-6.

Donaldson, W.E., 1995. Carbohydrate, hatchery stressors affect poult survival. In: Feedstuffs 67 (14), 16-17.

Donaldson, W.E., Christensen, V.L. \& Krueger, K.K., 1991. Effects of stressors on blood glucose and hepatic glycogen concentrations in turkey poults. Comp. Biochem. Physiol. A 100, 945-947.

Dreiling, C.E., Brown, D.E., Casale, L. \& Kelly, L., 1987. Muscle glycogen: comparison of iodine binding and enzyme digestion assays and application to meat samples. Meat Sci. 20, 167-177.

Edwards, M.R., McMurtry, J.P. \& Vasilatos-Younken, R., 1999. Relative insensitivity of avian skeletal muscle glycogen to nutritive status. Domest. Anim. Endocrinol. 16, 239-247.

Foye, O.T., Uni, Z. \& Ferket, P.R., 2006. Effect of in ovo feeding egg white protein, beta-hydroxy-betamethylbutyrate, and carbohydrates on glycogen status and neonatal growth of turkeys. Poult. Sci. 85, 1185-1192.

Francois, J. \& Parrou, J.L., 2001. Reserve carbohydrates metabolism in the yeast Saccharomyces cerevisiae. FEMS Microbiol. Rev. 25, 125-145.

Geyra, A., Uni, Z. \& Sklan, D., 2001. Enterocyte dynamics and mucosal development in the posthatch chick. Poult. Sci. 80, 776-782.

Johnston, S.A. \& Gous, R.M., 2007. Modelling the changes in the proportions of the egg components during a laying cycle. Br. Poult. Sci. 48, 347-353.

Leksrisompong, N., Romero-Sanchez, H., Plumstead, P.W., Brannan, K.E. \& Brake, J., 2007. Broiler incubation. 1. Effect of elevated temperature during late incubation on body weight and organs of chicks. Poult. Sci. 86, 2685-2691.

Lourens, A., Molenaar, R., Van den Brand, H., Heetkamp, M.J.W., Meijerhof, R. \& Kemp, B., 2006. Effect of egg size on heat production and the transition of energy from egg to hatchling. Poult. Sci. 85, 770-776.

Lourens, A., Van den Brand, H., Meijerhof, R. \& Kemp, B., 2005. Effect of eggshell temperature during incubation on embryo development, hatchability, and posthatch development. Poult. Sci. 84, 914-920. 
Lourens, A., Van den Brand, H., Heetkamp, M.J.W., Meijerhof, R. \& Kemp, B., 2007. Effects of eggshell temperature and oxygen concentration on embryo growth and metabolism during incubation. Poult. Sci. 86, 2194-2199.

Molenaar, R., Meijerhof, R., Kemp, B. Hulet, R. \& Van den Brand, H., 2009. High eggshell temperatures: A matter of life and death importance? Proc. IFRG meeting, Norwich, Norfolk, UK. pp. 25.

Moran Jr., E.T., 2007. Nutrition of the developing embryo and hatchling. Poult. Sci. 86, 1043-1049.

Noble, R.C. \& Cocchi, M., 1990. Lipid metabolism and the neonatal chicken. Prog. Lipid Res. 29, 107-140.

O'Dea, E.E., Fasenko, G.M., Feddes, J.J.R., Robinson, F.E., Segura, J.C., Ouellette, C.A. \& Van Middelkoop, J.H., 2004. Investigating the eggshell conductance and embryonic metabolism of modern and unselected domestic avian genetic strains at two flock ages. Poult. Sci. 83, 2059-2070.

Ohta, Y., Tsushima, N., Koide, K., Kidd, M.T. \& Ishibashi, T., 1999. Effect of amino acid injection in broiler breeder eggs on embryonic growth and hatchability of chicks. Poult. Sci. 78, 1493-1498.

Oloyo, R.A., 2003. Effect of age on total lipid and cholesterol of hen eggs. Indian J. Anim. Sci. 73, 94-96.

Peebles, E.D., Zumwalt, C.D., Doyle, S.M., Gerard, P.D., Latour, M.A., Boyle, C.R. \& Smith, T.W., 2000. Effects of breeder age and dietary fat source and level on broiler hatching egg characteristics. Poult. Sci. 79, 698-704.

Piestun, Y., Harel, M., Barak, M., Yahav, S. \& Halevy, O., 2009. Thermal manipulations in late-term chick embryos have immediate and longer term effects on myoblast proliferation and skeletal muscle hypertrophy. J. Appl. Physiol. 106, 233-240.

Powell, K.A., Deans, E.A. \& Speake, B.K., 2004. Fatty acid esterification in the yolk sac membrane of the avian embryo. J. Comp. Physiol. B. 174, 163-168.

Puvadolpirod, S. \& Thaxton, J.P., 2000. Model of physiological stress in chickens 4. Digestion and metabolism. Poult. Sci. 79, 383-390.

Richards, M.P., 1991. Mineral metabolism in the developing turkey embryo-II. The role of the yolk sac. Comp. Biochem. Physiol. A 100, 1017-1023.

Rizzi, C. \& Chiericato, G.M., 2005. Organic farming production. Effect of age on the productive yield and egg quality of hens of two commercial hybrid lines and two local breeds. Ital. J. Anim. Sci. 4, 160-1620.

SAS, 1985. Statistical Analysis System user's guide ( $5^{\text {th }}$ ed.). SAS Institute Inc., Carey, N.C., USA.

Sato, M., Tachibana, T. \& Furuse, M., 2006. Heat production and lipid metabolism in broiler and layer chickens during embryonic development. Comp. Biochem. Physiol. A. 143, 382-388.

Sell, J.L., 1996. Physiological limitations and potential for improvement in gastrointestinal tract function of poultry. J. Appl. Poult. Res. 5, 96-101.

Shafey, T.M., 1996. The relationship between age and egg production, egg components and lipoprotein, lipids and fatty acids of the plasma and eggs of laying hens. J. Appl. Anim. Res. 10, 155-162.

Shafey, T.M., Al-Batshan, H.A. \& Al-Samawei, K.A., 2009. In ovo feeding of chicken embyos. J. Saudi Soc. Agri. Sci. 9, 15-31.

Shafey, T.M., Al-Batshan, H.A., Al-Owaimer, A.N. \& AL-Samawei, K.A., 2010. Effects of in ovo administration of L-carnitine on hatchability performance, glycogen status and insulin-like growth factor-1 of broiler chickens. Br. Poult. Sci. 51, 122-131.

Silversides, F.G. \& Scott, T.A., 2001. Effect of storage and layer age on quality of eggs from two lines of hens. Poult. Sci. 80, 1240-1245.

Smirnov, A., Tako, E., Ferket, P.R. \& Uni, Z., 2006. Mucin gene expression and mucin content in the chicken intestinal goblet cells are affected by in ovo feeding of carbohydrates. Poult. Sci. 85, 669-673.

Speake, B.K. \& Powell, K.A., 2003. Differential incorporation of docosahexaenoic and arachidonic acids by the yolk sac membrane of the avian embryo. Comp. Biochem. Physiol. 136, 357-367.

Tako, E., Ferket, P.R. \& Uni, Z., 2004. Effects of in ovo feeding of carbohydrates and beta-hydroxy-betamethylbutyrate on the development of chicken intestine. Poult. Sci. 83, 2023-2028.

Uni, Z., Ganot, S. \& Sklan, D., 1998. Posthatch development of mucosal function in the broiler small intestine. Poult. Sci. 77, 75-82.

Uni, Z., Ferket, P.R., Tako, E. \& Kedar, O., 2005. In ovo feeding improves energy status of late-term chicken embryos. Poult. Sci. 84, 764-770.

Van den Brand, H., Parmentier, H.K. \& Kemp, B., 2004. Effects of housing system, (outdoor vs. cages) and age of laying hens on egg characteristics. Br. Poult. Sci. 45, 745-752. 
Vieira, S.L. \& Moran Jr., E.T., 1999. Effects of egg of origin and chick post-hatch nutrition on broiler live performance and meat yields. Wrld's Poult. Sci. J. 55, 125-142.

Wineland, M.J. \& Christensen, V.L., 2001. Impact of hatchery conditions on chicks. In: Completed Research. Dec. 2001. US Poult. Egg Assoc. pp. 29.

Wineland, M.J., Mann, K.M., Fairchild, B.D. \& Christensen, V.L., 2000a. Effect of high and low incubator temperatures at different stages of development upon the broiler embryo. Int. Poult. Sci. Forum abstract 180.

Wineland, M.J., Mann, K.M., Fairchild, B.D. \& Christensen, V.L., 2000b. Effect of different setter and hatcher temperatures upon the broiler embryo. Poult. Sci. 79 (Suppl. 1), S180.

Yilmaz-Dikmen, B. \& Sahan, U., 2009. The relationship among age, yolk fatty acids content, and incubation results of broiler breeders. Poult. Sci. 88, 185-190.

Zhai, W., Row, D.E. \& Peebles, E.D., 2011. Effects of commercial in ovo injection of carbohydrates on broiler embryogenesis. Poult. Sci. 90, 11295-1301. 